\title{
TIMELINESS OF CHILDHOOD VACCINE UPTAKE AMONG CHILDREN ATTENDING IMMUNOPROPHYLAXIS CLINIC IN CENTRAL INDIA
}

\author{
Durgesh Prasad Sahoo', Ashok Rupraoji Jadhao ${ }^{2}$, Jyotsna Sukhdeo Deshmukh³, Anchlesh Vinod Tekam ${ }^{4}$, Roshan Umedlal Raut $^{5}$ \\ ${ }_{1}^{1}$ Assistant Professor, Department of Community Medicine, Indira Gandhi Government Medical College, Nagpur. \\ 2Professor and Head, Department of Community Medicine, Indira Gandhi Government Medical College, Nagpur. \\ ${ }^{3}$ Associate Professor, Department of Community Medicine, Indira Gandhi Government Medical College, Nagpur. \\ ${ }^{4}$ Postgraduate student, Department of Community Medicine, Indira Gandhi Government Medical College, Nagpur. \\ 5 Postgraduate student, Department of Community Medicine, Indira Gandhi Government Medical College, Nagpur.
}

\section{ABSTRACT}

\section{BACKGROUND}

Child survival is dependent on many survival factors including immunisation. Even though, vaccines are provided free of cost at all government healthcare centers, the immunisation coverage in India is very low. Delayed vaccination not only increases the risk of vaccine preventable disease, but also increases the risk of never fully completing the vaccination course. The present study assessed the timeliness of immunisation for children below one year of age and factors influencing the timeliness of vaccination.

\section{MATERIALS AND METHODS}

This cross-sectional study was conducted at the Immunoprophylaxis Clinic (IPC) of a tertiary care hospital. Total 300 children were selected. All mothers/caretakers were interviewed. Chi-square test was used to find the difference between two proportions. Unadjusted odds ratio was calculated for various factors studied. Stepwise logistic regression analysis was done to calculate the adjusted odds ratio.

\section{RESULTS}

The overall delayed vaccination was found in 184 (61.3\%) babies while only $116(38.7 \%)$ babies were vaccinated on time without any delay. Education below secondary, lower socioeconomic classes, less than 4 ANC visits, birth order of 1 and 2 and those babies accompanied by other than mothers were significantly higher in "delayed group" when compared to "on time" group and also showed higher odds of $6.955,8.612,4.199,14.248,4.392$, respectively.

\section{CONCLUSION}

In this study, we found that mother's education, socioeconomic status, number of ANC visits, birth order and accompanied by mother or relatives affect the overall timeliness of immunisation.

\section{KEYWORDS}

Immunisation, Timeliness, ANC Visits, Birth Order.

HOW TO CITE THIS ARTICLE: Sahoo DP, Jadhao AR, Deshmukh JS, et al. Timeliness of childhood vaccine uptake among children attending immunoprophylaxis clinic in central India. J. Evolution Med. Dent. Sci. 2017;6(73):5232-5237, D0I: 10.14260/Jemds/2017/1136

\section{BACKGROUND}

Immunisation is one of the most cost-effective interventions preventing avoidable sickness, disability and death among under-five children. These benefits are not only restricted to improvement in health and life expectancy, but also have social and economic impact at both community as well as national level.(1) The world health organization estimates that vaccines annually prevent almost 6 million deaths worldwide.(2) The aim of routine immunisation program is to deliver complete number of doses of potent vaccine in a timely, safe and effective way to all children and women.(3)

Financial or Other, Competing Interest: None.

Submission 03-08-2017, Peer Review 28-08-2017,

Acceptance 02-09-2017, Published 11-09-2017.

Corresponding Author:

Dr. Ashok Rupraoji Jadhao,

Professor and Head,

Department of Community Medicine,

Indira Gandhi Government Medical College,

Nagpur-440018, Maharashtra, India.

E-mail: ashok_jadhao@yahoo.com

DOI: $10.14260 /$ jemds $/ 2017 / 1136$

(c) (i) $\ominus$
The current EPI schedule recommends BCG at birth; a total of 4 doses of primary bivalent oral polio vaccines at birth, 6 weeks, 10 weeks, 14 weeks and booster at 16-24 months of age; 3 doses of pentavalent-containing Diphtheria, Pertussis, Tetanus, Haemophilus influenza type $B$ and Hepatitis B at 6 weeks, 10 weeks, 14 weeks of age and Hepatitis B at birth; inactivated polio vaccines at 6 weeks and 14 weeks of age; measles and vitamin A1 at 9 months of age are administered to children less than one year of age.(4),(5)

Even though vaccines are provided free of cost at all government health centers, the immunisation coverage in India is as low as $62.0 \%$, and in Maharashtra, it is $56.3 \%$ amongst children of age 12-23 months (fully immunised).(6),(7) Delayed vaccination not only increases the risk of vaccine preventable disease, but also increases the risk of never fully completing the vaccination course.(8)

It was found that the recommended schedules for vaccination was not practiced commonly.(9) There are numerous factors like higher birth order of children, being unmarried, being in the lowest wealth quintile, living area, etc. lead to delayed uptake of vaccine.(10),(11) Considering this fact, the present study was undertaken in a tertiary care 
centre's Immunoprophylaxis Clinic (IPC) to assess the timeliness of immunisation for children below one year of age and factors influencing the timeliness of vaccination.

\section{MATERIALS AND METHODS}

This descriptive cross-sectional study was conducted at the Immunoprophylaxis Clinic (IPC) of a tertiary care institute in central India. The IPC attends an average of 2500 children per year and is open from Monday to Saturday except on weekends and public holidays. IPC provides immunisation services as per Universal Immunisation Program adopted by Government of Maharashtra.

Based on $87.3 \%$ of "on time" vaccination at $95 \%$ confidence interval, $5 \%$ absolute error, design effect of 1 and an estimated population of 2500 , the minimum sample size calculated using sample size calculation for single proportion was 160.(12),(13)

$\left\{\right.$ Formula $n=$ deff $* N p(1-p) /\left[d^{2} / 1.96 *(N-1)+p(1-p)\right]$

$\mathrm{n}=$ sample size

deff $=$ design effect $=1$

$\mathrm{N}=$ population size $=2500$

$\mathrm{P}=$ prevalence $=0.873$

$\mathrm{d}=$ desired precision $=5 \%\}$

Though the sample size estimated to be 160 , we had recruited 300 children for the study. After taking informed consent from all the respondents and after explanation of the purpose of the study, a pretested structured questionnaire was administered to all the respondents. The study duration was 3 months from April to June 2017. Timeliness of immunisation for BCG, OPV 0 , Hep B0, pentavalent $1 / 2 / 3$, OPV $1 / 2 / 3$, IPV $1 / 2$, measles and vitamin A1 was studied. All the children who had received measles vaccine and vitamin A1 at 9 months and those who have received booster dose of DPT/OPV/measles were enrolled for the study till the sample size reach 300 in IPC of study institute for timeliness of immunisation. Date of immunisation was verified from the immunisation card in possession of the respondents. If respondent was not having immunisation card, then immunisation registry record was seen for verification of dates of immunisation. Ethical approval for the study was taken from institutional ethics committee.

On the date of attending IPC, selected children were identified and questionnaire was administered. Details of previous vaccination was used as a part of data collection from the immunisation card provided by study center.(14) The data collection tool included the demographic factors, immunisation history, dates of previous immunisation, maternal information, distances to health facility, antenatal records and delivery history were collected from their mothers or relatives accompanying the child. Education was classified according to Indian Standard Classification of Education(15) and socioeconomic status was classified using the modified B G Prasad Classification.(16)

The timeliness of vaccination was determined based on immunisation schedule adopted by Government of Maharashtra for a specific vaccine as follows.

\section{On Time}

If the child received vaccine on or within two weeks after scheduled date.

\section{Accepted Delayed}

If the child received between 2 and 4 weeks after scheduled date.

\section{Delayed}

If the child received after 4 weeks of scheduled date.

The timeliness of vaccination was calculated by subtracting the expected date of vaccination based on date of birth of the child from the date of administration of specific vaccines.

Children who all fall into acceptably delayed or in the delayed group even for a single vaccine was considered as "delayed group" while children who all received all the vaccines on time was considered as "on time" group for comparison of various factors.

\section{Statistical Analysis}

The data was analysed using SPSS version 20.0. The quantitative variables were expressed in terms of mean and standard deviation and the qualitative variables were expressed in percentages. Chi-square test was used to find the difference between two proportions. Unadjusted odds ratio was calculated for various factors studied. Stepwise logistic regression analysis was done to calculate the adjusted odds ratio.

\section{RESULTS}

Total 300 participants enrolled after informed consent of mother or relative accompanied the child at immunoprophylaxis clinic of a tertiary care center in Central India who had received measles vaccine and vitamin A1 at 9 months and those who have received booster dose of DPT/OPV/measles.

\begin{tabular}{|c|c|c|c|}
\hline \multicolumn{2}{|c|}{ Demographic Variables } & Frequency & $\%$ \\
\hline \multirow{2}{*}{$\begin{array}{l}\text { Age of mother } \\
\text { in years }\end{array}$} & Less than 30 years & 230 & 76.7 \\
\hline & 30 years or more & 70 & 23.3 \\
\hline \multirow{2}{*}{ Gender } & Female & 147 & 49.0 \\
\hline & Male & 153 & 51.0 \\
\hline \multirow{6}{*}{ Education } & Illiterate & 12 & 4.0 \\
\hline & Primary & 27 & 9.0 \\
\hline & Upper primary & 53 & 17.7 \\
\hline & Secondary & 93 & 31.0 \\
\hline & Senior secondary & 78 & 26.0 \\
\hline & Graduate & 37 & 12.3 \\
\hline \multirow{5}{*}{$\begin{array}{c}\text { Socioeconomic } \\
\text { status }\end{array}$} & I & 23 & 7.7 \\
\hline & II & 41 & 13.7 \\
\hline & III & 81 & 27.0 \\
\hline & IV & 90 & 30.0 \\
\hline & $\mathrm{V}$ & 65 & 21.7 \\
\hline \multirow{2}{*}{ Occupation } & Homemaker & 266 & 88.7 \\
\hline & Working & 34 & 11.3 \\
\hline \multirow{2}{*}{$\begin{array}{c}\text { Time taken to } \\
\text { reach IPC }\end{array}$} & Less than 30 minutes & 175 & 58.3 \\
\hline & More than 30 minutes & 125 & 41.7 \\
\hline \multirow{2}{*}{$\begin{array}{l}\text { Mode of } \\
\text { transport }\end{array}$} & Own vehicle/on foot & 156 & 52.0 \\
\hline & Public transport & 144 & 48.0 \\
\hline \multirow{2}{*}{$\begin{array}{l}\text { Accompanied } \\
\text { by }\end{array}$} & Mother & 198 & 66.0 \\
\hline & Others & 102 & 34.0 \\
\hline
\end{tabular}

Table 1. Demographic Characteristics of the Study Subjects 
Table 1 shows socioeconomic and demographic information. There was a total of $153(51.0 \%)$ males and 147 females $(49.0 \%)$ of study subjects. The mean age of the children was $14.15 \pm 3.51$ months, median age of 14.0 months and range of 9 to 22 completed months. The mean age of mother was $26.20 \pm 4.51$ years and a range of 18 to 37 years. Majority of the mothers were less than 30 years 230 (76.7\%) while $208(69.3 \%)$ of the mothers studied secondary and above. Around half of the mothers belonged to lower class 155 (class IV and class $\mathrm{V}=51.7 \%$ ) as per modified B.G. Prasad classification. Most of the mothers were homemakers $266(88.7 \%)$. Using own vehicle or by walking was the most commonly used mode of transports 156 (52.0\%) with an average time of $24.24 \pm 16.43$ minutes with a median of 20 minutes. Majority of the children were accompanied by their mothers 198 (66.0\%).

\begin{tabular}{|c|c|c|c|}
\hline \multicolumn{2}{|c|}{ Obstetric Variable } & Frequency & Percent \\
\hline ANC visits & Yes & 300 & 100 \\
\hline \multirow{2}{*}{ Number of ANC visits } & Less than 4 & 29 & 9.7 \\
\hline & 4 or more & 271 & 90.3 \\
\hline \multirow{3}{*}{ Birth order } & 1 & 174 & 58 \\
\hline & 2 & 99 & 33 \\
\hline & 3 or more & 27 & 9 \\
\hline Place of delivery & Hospital & 300 & 100 \\
\hline \multirow{3}{*}{ Mode of delivery } & Vaginal & 166 & 55.3 \\
\hline & Forceps & 11 & 3.7 \\
\hline & Cesarean & 123 & 41 \\
\hline \multicolumn{4}{|c|}{$\begin{array}{l}\text { Table 2. Distribution of the Study } \\
\text { Subjects as per Obstetrics Variable }\end{array}$} \\
\hline
\end{tabular}

Table 2 shows distribution of study subjects as per obstetrics information. All the mothers attended ANC visits during pregnancy period and 271 (90.3\%) of mothers made 4 or more ANC visits. All the mothers were delivered in health institution. Out of all the 300 babies delivered, 123 (41.0\%) were delivered by caesarean section and the remainder by spontaneous or assisted vaginal delivery. Majority of the babies were of birth order one 174 (58.0\%).

\begin{tabular}{|c|c|c|c|}
\hline Vaccine & On time & $\begin{array}{l}\text { Acceptably } \\
\text { Delayed }\end{array}$ & Delayed \\
\hline BCG & $272(90.7 \%)$ & $21(7.0 \%)$ & $7(2.3 \%)$ \\
\hline OPV 0 & $272(90.7 \%)$ & & \\
\hline Hep B 0 & $232(77.3 \%)$ & & \\
\hline $\begin{array}{c}\text { Pentavalent1/OPV1/ } \\
\text { IPV1 }\end{array}$ & $228(76.0 \%)$ & $41(13.7 \%)$ & $31(10.3 \%)$ \\
\hline Pentavalent2/OPV2 & $199(66.3 \%)$ & $65(21.7 \%)$ & $36(12.0 \%)$ \\
\hline $\begin{array}{c}\text { Pentavalent3/OPV3/ } \\
\text { IPV2 }\end{array}$ & $188(62.7 \%)$ & $61(20.3 \%)$ & $51(17.0 \%)$ \\
\hline Measles/vitamin A1 & $219(73.0 \%)$ & $41(13.7 \%)$ & $40(13.3 \%)$ \\
\hline \multicolumn{4}{|c|}{ Overall delayed $=184(61.3 \%)$, On time $=116(38.7 \%)$} \\
\hline
\end{tabular}

Table 3 shows timeliness of vaccine uptake by study subjects. Majority of the babies were vaccinated for BCG and OPV 0 dose 272 (90.7\%). Only 9.3\% got delayed vaccination for BCG and OPV 0 as mothers/relatives informed due to sickness of the babies, low birth weight babies, mother's ill health or no reason, etc. The "on time" vaccination percentage was decreased as the immunisation schedule progressed for primary immunisation OPV/pentavalent/IPV ( 6 weeks $>10$ weeks $>14$ weeks). On time vaccination at completed 9 months for measles and vitamin $\mathrm{A}_{1}$ was slightly higher 219 (73.0\%). OPV 0 and Hep B 0 are not to be administered after 14 days. Hence, it was not assessed. The overall delayed vaccination was found in 184 (61.3\%) babies, while only 116 $(38.7 \%)$ babies were vaccinated on time without any delay.

\begin{tabular}{|c|c|c|c|c|c|}
\hline \multirow{2}{*}{ Variables } & \multicolumn{2}{|c|}{ Group } & \multirow{2}{*}{$\begin{array}{l}\text { Odd's Ratio (Confidence } \\
\text { Interval) }\end{array}$} & \multirow{2}{*}{ Chi-Square } & \multirow{2}{*}{ p value } \\
\hline & Delayed & On Time & & & \\
\hline \multicolumn{6}{|c|}{ Age of Mother in Years } \\
\hline Less than 30 years & $148(64.4 \%)$ & $82(35.6 \%)$ & Reference value & \multirow{2}{*}{3.777} & \multirow{2}{*}{0.052} \\
\hline 30 years or more & $36(51.4 \%)$ & $34(48.6 \%)$ & $0.587(0.342,1.008)$ & & \\
\hline \multicolumn{6}{|c|}{ Gender } \\
\hline Female & $85(57.8 \%)$ & $62(42.2 \%)$ & Reference value & \multirow{2}{*}{1.498} & \multirow{2}{*}{0.221} \\
\hline Male & $99(64.7 \%)$ & $54(35.3 \%)$ & $1.337(0.839,2.131)$ & & \\
\hline \multicolumn{6}{|c|}{ Education } \\
\hline Upto Secondary & $145(78.4 \%)$ & $40(21.4 \%)$ & $7.064(4.195,11.895)$ & \multirow{2}{*}{59.123} & \multirow{2}{*}{$0.0001^{*}$} \\
\hline Above Secondary & $39(33.9 \%)$ & $76(66.1 \%)$ & Reference value & & \\
\hline \multicolumn{6}{|c|}{ Socioeconomic Status } \\
\hline I, II, III & $55(37.9 \%)$ & $90(62.1 \%)$ & $8.119(4.738,13.912)$ & \multirow{2}{*}{64.810} & \multirow[b]{2}{*}{$0.0001^{*}$} \\
\hline $\mathrm{IV}, \mathrm{V}$ & $129(83.2 \%)$ & $26(16.8 \%)$ & Reference value & & \\
\hline \multicolumn{6}{|c|}{ Occupation } \\
\hline Homemaker & $161(60.5 \%)$ & $105(39.5 \%)$ & Reference value & \multirow{2}{*}{0.645} & \multirow{2}{*}{0.422} \\
\hline Working & $23(67.6 \%)$ & $11(32.3 \%)$ & $1.364(0.638,2.914)$ & & \\
\hline \multicolumn{6}{|c|}{ Number of ANC Visits } \\
\hline Less than 4 & $23(79.3 \%)$ & $6(20.7 \%)$ & $2.619(1.033,6.642)$ & \multirow{2}{*}{4.375} & \multirow{2}{*}{$0.036^{*}$} \\
\hline 4 or more & $161(59.4 \%)$ & $110(40.6 \%)$ & Reference value & & \\
\hline \multicolumn{6}{|c|}{ Birth Order } \\
\hline 1,2 & $178(65.0 \%)$ & $96(35.0 \%)$ & $6.181(2.401,15.909)$ & \multirow{2}{*}{17.568} & \multirow{2}{*}{$0.0001^{*}$} \\
\hline 3 or more & $6(23.1 \%)$ & $20(76.9 \%)$ & Reference value & & \\
\hline \multicolumn{6}{|c|}{ Time Taken to Reach IPC } \\
\hline Less than 30 minutes & $105(60.0 \%)$ & $70(40.0 \%)$ & Reference value & \multirow{2}{*}{0.315} & \multirow{2}{*}{0.574} \\
\hline More than 30 minutes & $79(63.2 \%)$ & $46(36.8 \%)$ & $1.145(0.714,1.837)$ & & \\
\hline
\end{tabular}




\begin{tabular}{|c|c|c|c|c|c|}
\hline \multicolumn{7}{|c|}{ Mode of Transport } \\
\cline { 1 - 4 } Own vehicle/on foot & $96(61.5 \%)$ & $60(38.5 \%)$ & Reference value & \multirow{2}{*}{0.006} & \multirow{2}{*}{0.939} \\
\hline Public transport & $88(61.1 \%)$ & $56(38.9 \%)$ & $0.982(0.617,1.564)$ & \multirow{2}{*}{8.197} & \multirow{2}{*}{$0.004^{*}$} \\
\hline \multicolumn{7}{|c|}{ Accompanied by } \\
\hline Mother & $110(55.6 \%)$ & $88(44.4 \%)$ & Reference value & $2.114(1.260,3.547)$ & \\
\hline Other & $74(72.5 \%)$ & $28(27.5 \%$ & Table 4. Factors Related to Timeliness of Vaccination Group \\
\hline
\end{tabular}

*Significant values.

Table 4 depicts education below secondary, lower socioeconomic classes, less than 4 ANC visits, birth order of 1 and 2 and those babies accompanied by other than mothers were significantly higher in "delayed group" when compared to "on time" group and also showed higher odds. However, age of mother less than 30 years, male babies, working mothers, time taken more than 30 minutes to reach IPC were more in "delayed group" when compared to "on time" group, but it was not statistically significant.

\begin{tabular}{|c|c|c|c|}
\hline Variables & $\begin{array}{c}\text { Odds } \\
\text { Ratio }\end{array}$ & $\begin{array}{c}\text { 95\% Confidence } \\
\text { Interval }\end{array}$ & P value \\
\hline Socioeconomic status & 8.612 & $4.471,16.592$ & $0.0001^{*}$ \\
\hline Education & 6.955 & $3.664,13.203$ & $0.0001^{*}$ \\
\hline Birth order & 14.248 & $4.212,48.194$ & $0.0001^{*}$ \\
\hline Number of ANC visits & 4.199 & $1.249,14.109$ & $0.02^{*}$ \\
\hline Accompanied by & 4.392 & $2.150,8.973$ & $0.0001^{*}$ \\
\hline $\begin{array}{c}\text { Table 5. Multivariate Analysis of the Factors Associated with } \\
\text { Delayed Vaccination in the Study Population (Final Model) }\end{array}$ \\
\hline
\end{tabular}

Cox and Snell R square $=0.387$, Nagelkerke $\mathrm{R}$ square $=$ 0.526 *Significant.

For lower economic status, lower education, lower birth order, less number of ANC visits and babies accompanied by other than mothers, the odds ratio was higher, 8.612, 6.955, $14.248,4.199$ and 4.392, respectively for delayed vaccination. The Cox and Snell $\mathrm{R}^{2}$ and Nagelkerke $\mathrm{R}^{2}$ explains between $38.7 \%$ and $52.6 \%$ of the variance of all the above variables for timeliness of vaccination.

\section{DISCUSSION}

This descriptive cross-sectional study inferred that only $38.7 \%$ of the babies were vaccinated on time without any delay and $61.3 \%$ of the babies got over all delayed vaccination (delayed by more than 14 days). Proportion of "on time" vaccination for BCG and OPV 0 was $90.7 \%$, while it was decreased as the immunisation schedule progressed.

In a study conducted by Laryea D 0 et al in a tertiary health services facility in Ghana, overall $87.3 \%$ of babies received vaccine on time, which was higher as compared to our study. However, the proportion of on-time vaccination for BCG and measles were $88.9 \%$ and $50.5 \%$, which were comparatively lower as compared to our study.(12) Another study conducted by Holambe VM et al at a tertiary care center of Maharashtra, $66 \%$ of the babies presented on time for vaccination, which was similar to our study.(17)

In our study, delayed vaccination was more when the age of the mothers were less than 30 years, i.e. $64.4 \%$ compared to mothers with age 30 years and above, but the difference was not significant. This finding was similar to a study conducted by Luman ET et al where mothers who all had age more than 30 years got less severely delayed vaccination $(17.9 \%)$ for babies as compared to mothers who had age of 20-30 years and less than 20 years $(22.9 \%$ and $28.7 \%$, respectively).(9) Similar findings were observed by Holambe VM et al and Cotter JJ et al.(17),(18)

Delayed vaccination was more in male babies (64.7\%) as compared to female babies (54.8\%) in our study. Similar findings were found by Holambe VM et al that females were vaccinated more $(53.08 \%)$ on time as compared to males $(46.92 \%)$ and this association was not significant $(\mathrm{p}$ value $=$ 0.479).(17) Another study conducted by Huggins L J on immunisation status of NICU graduates found no association between gender and immunisation.(19)

The association between education and timeliness of vaccination was highly significant. Similar findings were observed by Sadoh AE et al conducted a study on Nigerian infants and Luman ET et al where education played one important role for timeliness of vaccination.(20),(9) Mothers with higher education group got more timely vaccination of babies as compared to lower education group.

Delayed vaccination was more in lower socioeconomic classes (83.2\%) as compared to higher classes (37.9\%) and the difference was significant. Similar findings were observed by Sadoh AE et al where on time vaccinations for class I, class II, class III and class IV were $75 \%, 52 \%, 50 \%$ and $25 \%$, respectively and the difference was significant.(20)

In this study, working mothers made more delayed vaccinations $(67.6 \%)$ for their babies as compared to housemakers (60.5\%). A study conducted by Rahji F R et al found that housewives got significantly less compliance in immunisation than working mothers.(21)

Mothers with less than 4 ANC visits had significantly more $(79.3 \%)$ of delayed vaccinations for their babies as compared to mothers with more than 4 ANC visits (59.4\%). A study conducted by Bisiriyu L et al in Nigeria observed similar results where women with 4 ANC visits plus got $50.8 \%$ full vaccination as compared to women with less than 4 ANC visits (12.5\%).(22) There was a strong and significant relation observed by Meredith et al between number of ANC visits and EPI attendance.(23)

The study showed a significant difference in delay in vaccination for children with lower birth order. This may be explained by the fact that mothers with high parity might have more experience on child rearing practices and better knowledge on immunisation. This is in contrary to studies done by Ramaswamy G et al, Fadness LT et al, Holambe VM et al where delayed vaccination was more common in higher birth order.(24),(11),(17) Another study conducted by Nilanjan Patra in three states of India (Bihar, Tamil Nadu and West Bengal) found association of lower birth order with delayed vaccination, which is similar to our study findings.(25) 
In this study, delayed vaccination was more when time taken to reach IPC was more than 30 minutes. Similar results were found by Ndiritu $\mathrm{M}$ et al that immunisation rate ratio were reduced with every increasing kilometer of distance from home to vaccine clinic ( $\mathrm{HR}=0.95 ; \mathrm{CI}=0.91,1.00)$. ${ }^{(26)}$ Another study conducted by Xeuatvongsa A et al found that fully immunised proportion was significantly more when time taken to reach nearest health facilities was less than 30 minutes $(69.52 \%)$ as compared to when it was more than 30 minutes $(30.48 \%) .(27)$

The proportion of delayed vaccination when used public transport (61.5\%) or own vehicle/on foot (61.1\%) as mode of transport was almost equal. In contrary to this, a study conducted by Vonasek $\mathrm{BJ}$ et al found higher odds $(\mathrm{OR}=$ 1.103) of full vaccination for those mothers/relatively rely on walking for transportation to vaccination facility.(28)

Delayed vaccination was significantly higher when the babies were accompanied by relatives apart from mothers. This may be explained by the fact that mothers were more concerned about the health status of their own babies as compared to other relatives and the babies were more comfortable with their mothers as compared to other relatives.

Samples of the present study may not be representative of the population since we selected only one tertiary care center from Central India. Since, this was a descriptive crosssectional study, a cause and effect relationship between timeliness of vaccination and risk factors was difficult to assess. In spite of these limitations, the study can give certain insight about the timeliness vaccination of the children of the Central India.

\section{CONCLUSION}

In this study, higher proportion of overall delayed vaccination was found in Central India. We also found that higher proportions of on-time vaccinations for BCG, OPV 0 and measles. Further, we found that mother's education, socioeconomic status, number of ANC visits, birth order and accompanied by mother or relatives affect the overall timely immunisation on a long run.

Socioeconomic development needs to be ensured. Special efforts has to be made to sensitise pregnant women about the importance of ANC visits, programs that will help women in developing familiarity with our healthcare systems; so that they can rely on our healthcare services again for the benefits of their children.

\section{ACKNOWLEDGEMENT}

We would like to thank all our IPC staffs for their support during the study and to the children and their caretakers who participated in this study.

\section{REFERENCES}

[1] Immunisation| UNICEF. Available from: http://unicef.in/Whatwedo/3/Immunisation.

[2] WHO | Vaccination greatly reduces disease, disability, death and inequity worldwide. WHO 2011. Available from:

http://www.who.int/bulletin/volumes/86/2/07040089/en
[3] Maternal knowledge and perceptions about the routine immunisation programme -a study in a semi urban area in Rajasthan 2003. Available from: https://www.researchgate.net/publication/20230316 7_Maternal_Knowledge_and_Perceptions_about_the_R outine_Immunisation_Programme_-

A_study_in_a_semi_urban_area_in_Rajasthan.

[4] Immunisation schedule-expanded programme, who recommendations-immunisation. Available from: http://www.pediatriconcall.com/forpatients/vaccinat ion/article.aspx?artid=390.

[5] WHO | Fractional dose IPV. WHO 2017. Available from: http://www.who.int/immunisation/diseases/poliomy elitis/endgame_objective2/inactivated_polio_vaccine/ fractional_dose/en

[6] NFHS-4. National family health survey India 20152016. 2016:1-8.

[7] Indian institute for population sciences. National family health survey-4, 2015-16. State fact sheet, Maharashtra 2015:1-6.

[8] Guerra FA. Delays in immunisation have potentially serious health consequences. Pediatr Drugs 2007;9(3):143-8.

[9] Luman ET, Barker LE, Shaw KM, et al. Timeliness of childhood vaccinations in the United States: days under vaccinated and number of vaccines delayed. JAMA 2005;293(10):1204-11.

[10] Babirye JN, Engebretsen IM, Makumbi F, et al. Timeliness of childhood vaccinations in Kampala, Uganda: a community-based cross-sectional study. PLoS One 2012;7(4):e35432.

[11] Fadnes LT, Jackson D, Engebretsen IM, et al. Vaccination coverage and timeliness in three South African areas: a prospective study. BMC Public Health 2011;11:404.

[12] Laryea DO, Parbie AE, Frimpong E. Timeliness of childhood vaccine uptake among children attending a tertiary health service facility-based immunisation clinic in Ghana. BMC Public Health 2014;14:90.

[13] Sullivan KM. Sample Size for a Proportion 2003;1-2.

[14] Mother child protection card CBT-programmes-health education to villages. Available from: http://hetv.org/programmes/mother-childprotection-card-cbt.htm.

[15] Department of higher education. Indian standard classification of education. Minist Hum Resour Dev Gov India 2014:1-72. Available from: http://mhrd.gov.in/sites/upload_files/mhrd/files/sta tistics/InSCED2014_1.pdf.

[16] Prasads social classification for 2017. Available from: http://prasadscaleupdate.weebly.com.

[17] Holambe VM, Thakur NA. Correlates of delayed immunisation: a cross-sectional study at a tertiary care centre of Maharashtra, India. Natl J Community Med 2013;4(4):621-3.

[18] Cotter JJ, Bramble JD, Bovbjerg VE, et al. Timeliness of immunisations of children in a medicaid primary care case management managed care program. J Natl Med Assoc 2002;94(9):833-40.

[19] Huggins LJ, Huggins LJ. Immunisation status of NICU graduates at a tertiary care children's hospital 2016. 
[20] Sadoh AE, Sadoh WE, Uduebor J, et al. Factors contributing to delay in commencement of immunisation in Nigerian infants. Tanzania Journal of Health Research 2013;15(3):1-8.

[21] Rahji FR, Ndikom CM. Factors influencing compliance with immunisation regimen among mothers in Ibadan, Nigeria. IOSR J Nurs Heal Sci 2013;2(2):2320-1940.

[22] Bisiriyu L, Ojewumi TK. Mothers' health seeking behaviour and socioeconomic differentials: a factor analysis of full childhood immunisation in SouthWestern Nigeria. J Public Heal Epidemiol 2014;6(3):132-47.

[23] Carlson M, Paintain SL, Bruce J, et al. Who attends antenatal care and expanded programme on immunisation services in Chad, Mali and Niger? The implications for insecticide-treated net delivery. Malar J 2011;10:341.

[24] Ramaswamy G, Pruthu TK, Selvaraj K, et al. Timeliness of primary childhood vaccination in a rural area of Puducherry, South India: evidence from routine management information system. Int J Contemp Pediatr 2014;1(3):131-4.
[25] Patra N. Universal immunisation programme in India: the determinants of childhood immunisation. SSRN Electron J 2006.

[26] Ndiritu M, Cowgill KD, Ismail A, et al. Immunisation coverage and risk factors for failure to immunize within the expanded programme on immunisation in Kenya after introduction of new haemophilus influenzae type B and hepatitis B virus antigens. BMC Public Health 2006;6:132.

[27] Xeuatvongsa A, Hachiya M, Miyano S, et al. Determination of factors affecting the vaccination status of children aged 12-35 months in Lao people's democratic republic. Heliyon 2017;3(3):e00265.

[28] Vonasek BJ, Bajunirwe F, Jacobson LE, et al. Do maternal knowledge and attitudes towards childhood immunisations in rural Uganda correlate with complete childhood vaccination? PLoS One 2016;11(2):e0150131. 